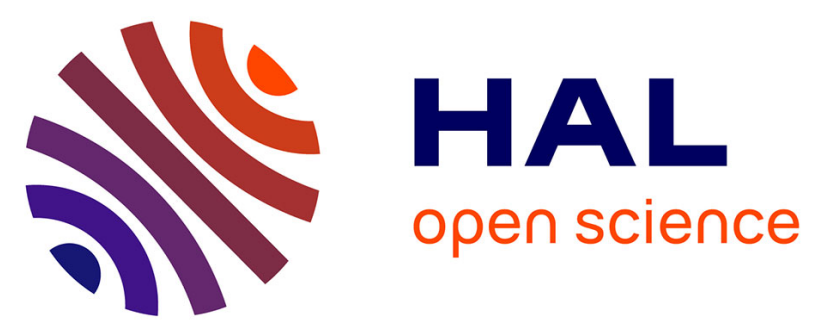

\title{
RELATION BETWEEN ELECTROCHEMICAL REACTIVITY AND STRUCTURE OF GRAIN BOUNDARIES CORRELATED TO INTERGRANULAR SULFUR SEGREGATION IN ULTRA PURE NICKEL
}

Luc Beaunier, Colette Vignaud, D. Bouchet, C. Colliex, P. Trebbia

\section{To cite this version:}

Luc Beaunier, Colette Vignaud, D. Bouchet, C. Colliex, P. Trebbia. RELATION BETWEEN ELECTROCHEMICAL REACTIVITY AND STRUCTURE OF GRAIN BOUNDARIES CORRELATED TO INTERGRANULAR SULFUR SEGREGATION IN ULTRA PURE NICKEL. Journal de Physique Colloques, 1985, 46 (C4), pp.C4-505-C4-515. 10.1051/jphyscol:1985456 . jpa-00224707

HAL Id: jpa-00224707 https://hal.science/jpa-00224707

Submitted on 1 Jan 1985

HAL is a multi-disciplinary open access archive for the deposit and dissemination of scientific research documents, whether they are published or not. The documents may come from teaching and research institutions in France or abroad, or from public or private research centers.
L'archive ouverte pluridisciplinaire HAL, est destinée au dépôt et à la diffusion de documents scientifiques de niveau recherche, publiés ou non, émanant des établissements d'enseignement et de recherche français ou étrangers, des laboratoires publics ou privés. 


\title{
RELATION BETWEEN ELECTROCHEMICAL REACTIVITY AND STRUCTURE OF GRAIN BOUNDARIES CORRELATED TO INTERGRANULAR SULFUR SEGREGATION IN ULTRA PURE NICKEL
}

\author{
L. Beaunier, C. Vignaud, D. Bouchet ${ }^{+}$, C. Colliex ${ }^{++}$and P. Trebbia ${ }^{++}$ \\ Laboratoire Physique des Liquides et Electrochimie, CRNS, LP 15, Université \\ Paris VI, $T$ 22, 4, place Jussieu, 75230 Paris Cedex 05, France \\ +Laboratoire de Métalzurgie Physique, LA 177, Université Paris Sud, \\ Centre d'orsay, Bât. 413, 91405 Orsay Cedex, France \\ ${ }^{++}$Laboratoire de Physique du Solide, Université Paris Sud, Centre d'orsay, \\ Bât. 410, 91405 Orsay Cedex, Erance
}

\begin{abstract}
Résumé - Dans un nickel uTtra pur dopé à 8 et 16 ppm de soufre, nous avons caractérisé la cinétique de ségrégation et l'état d'équilibre des joints de grains ségrégés en soufre grâce à un test de corrosion électrochimique. Le nickel de base et 1 'échantillon le plus ségrégé sont observés au microscope êlectronique à transmission afin d'établir un histogramme de la structure des joints de grains étudiés et de déterminer les paramètres cristallographiques des joints les plus chargés en soufre. Ces résultats sont corrêlés avec la réactivité électrochimique et l'analyse quantitative en microscopie êlectronique à balayage à transmission.

Abstract - In a ultra pure nickel doped with 8 and $16 \mathrm{ppm}$ of sulfur, we have determined the kineticsand equilibrium state of segregated sulfur at grain boundaries by electrochemical corrosion test. The undoped nickel and the highest segregated specimen are observed in transmission electron microscopy in order to correlate the structural histogram with electrochemical reactivity study and analytical scanning transmission electron microscope experiments.
\end{abstract}

Even at very low concentration (few ppm) the presence of sulfur in nickel and nickel alloys givesrise to intergranular segregation. This is known to alter significantly grain boundary properties, especially embrittlement and intergranular corrosion susceptibility $/ 1,2 /$.

In the case of intergranular corrosion, the process is governed by the atomic interaction but the details will depend on the atomic structure of grain boundaries and segregation.

The segregation level is controlied by the nature and concentration of present elements and the structure of the grain boundaries. Theoretical studies have been developed in order to understand the nature of segregation sites $/ 3,4 /$ and the effect of the atomic structure disturbance by electronic structure (Ni-S chemical bonding) $15 /$. Previous works have discussed the variation of the amount of segregation with grain boundary type $/ 6,7,8 /$ : segregation occurs preferentially to high energy boundaries which have more segregation sites and then reduces their energy more than low ones. The different energy reduction for random and special grain boundaries tends to equalize the energies.

The present paper shows experimental results of correlation between corrosion reactivity, grain boundary structure and the amount of segregated sulfur at grain boundaries in a very high purity nickel. 


\section{MATERIALS}

The high purity nickel $\mathrm{Ni}-\mathrm{OS}$ is a vacuum plasma melted nickel which contains $160 \mathrm{ppm}$ $\mathrm{Si}$ in weight, $45 \mathrm{ppm} \mathrm{Na}$ and $\mathrm{S}, \mathrm{P}, \mathrm{Pt}, \mathrm{Fe}, \mathrm{Cu}, \mathrm{Cr}, \mathrm{Ca}, \mathrm{As}, \mathrm{Al}$, less than $2 \mathrm{ppm}$. This metal is doped with 8 and $16 \mathrm{ppm} S$ in order to have an alloy each side of the 1 imit of solubility for sulfur in nickel at $10 \mathrm{ppm} / 9 /$. Specimens are named respectively $\mathrm{Ni}-8 \mathrm{~S}$ and $\mathrm{Ni}-16 \mathrm{~S}$. The three metals are cold rolled at $80 \%$ (thickness $5 \mathrm{~mm}$ ) and annealed in quartz tube with argon hydrogen atmosphere, firstly at $1050^{\circ} \mathrm{C}-4$ hours to develop and stabilize grain boundaries structure, secondly at segregation temperature $625^{\circ} \mathrm{C}$ determined in a previous work $/ 2 /$ for different times up to 12 days.

\section{I - ELECTROCHEMICAL REACTIVITY OF GRAIN BOUNDARIES}

\section{EXPERIMENTALS}

In an earlier work we have performed an electrochemical test whose sensibility is proportional to the level of segregation in grain boundaries $12,10 \%$. This experiment is based on the attack of $\mathrm{Fe}-\mathrm{Ni}-\mathrm{Cr}$ alloys at transpassive electrochemical potential in sulfuric acid solution $\mathrm{H}_{2} \mathrm{SO}_{4}-2 \mathrm{~N}-25^{\circ} \mathrm{C}$. Current and potential parameters are chosen and the quantity of electricity $\left(20 \mathrm{C} / \mathrm{cm}^{2}\right)$ is rigorously controlled in order to dissolve a known quantity of metal. The intergranular attack develops a triangular groove at the emergence of grain boundaries on the surface. We measure the depth $D$, the width $W$ and the dihedral angle $\alpha$ with a scanning electron microscope. We have a particular attention for the depth which is proportional to the amount of sulfur segregation and is measured for each grain boundary /2/ with respect to its individuality. The average value of twenty measures gives the global evaluation for each specimen.

\section{RESULTS}

Aspects of surface corrosion are given on the micrographs $1 \mathrm{a}$ and $1 \mathrm{~b}$ respectively for $\mathrm{Ni}-\mathrm{OS}, 1050^{\circ} \mathrm{C}-4$ hours, and $\mathrm{Ni}-16 \mathrm{~S}, 1050^{\circ} \mathrm{C}-4$ hours $+625^{\circ} \mathrm{C}-2$ days. We observe the presence of low energy grain boundaries and coherent twins which are less attacked than high energy grain boundaries and incoherent twins. This classification has been demonstrated on stainless steel bicrystals /11/ and confirmed on Ni-0S bicrystals /12/. This is coherent with the fact that a grain boundary without impurity segregation is poorly attacked $/ 13 /$.

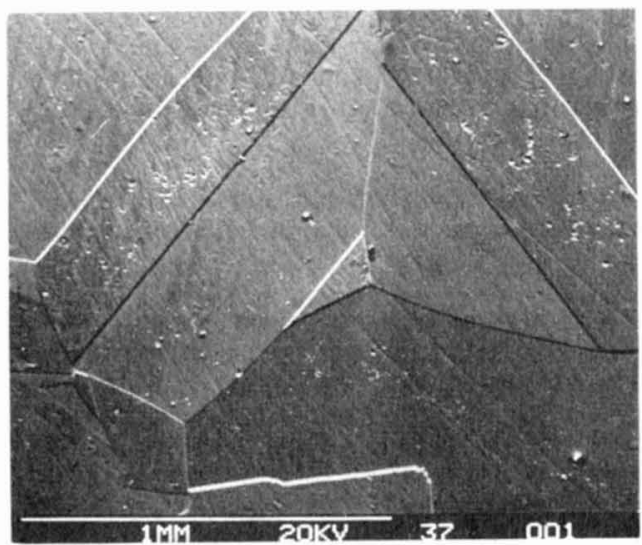

Fig. Ia - Pure Ni, $1050^{\circ} \mathrm{C}-4$ hours.

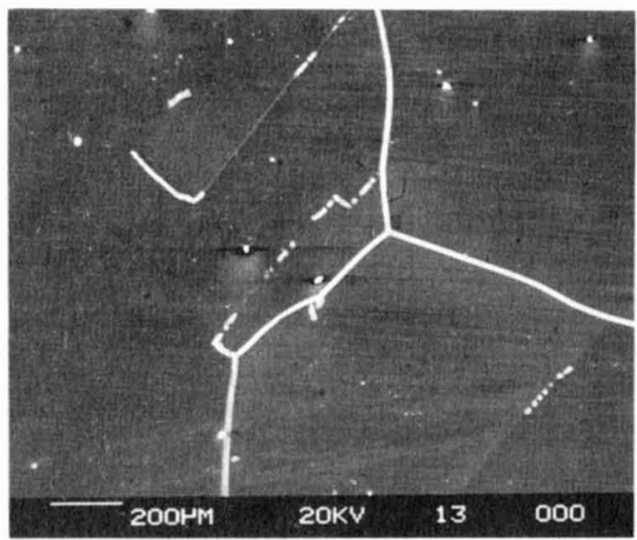

Fig. $1 \mathrm{~b}-\mathrm{Ni}-16 \mathrm{~S}, 1050^{\circ} \mathrm{C}-4$ hours + $625^{\circ} \mathrm{C}-2$ days.

The micrographs $2 a$ and $2 b$ allow to compare the features of the ultra pure nicke1 groove and these of $\mathrm{Ni}-16 \mathrm{~S}$ respectively for an annealing of $1050^{\circ} \mathrm{C}-4$ hours $+625^{\circ} \mathrm{C}$ - 2 days corresponding to the maximum corrosion level. 
Figure 3 gives the evolution of the dihedral angle $\alpha$ versus segregation heat treatment time at $625^{\circ} \mathrm{C}$. This angle is inversely proportional to the segregated sulfur concentration. Up to two days of annealing the angle reaches a constant value : $\alpha=55^{\circ}$ for $\mathrm{Ni}-8 \mathrm{~S}$ and $\alpha=45^{\circ}$ for $\mathrm{Ni}-16 \mathrm{~S}$. The first part of the curve corresponds to the kinetical evolution of the segregation and the second part to the stable equilibrium segregation. We remark that the angle is larger for $\mathrm{Ni}-8 \mathrm{~S}$ which corresponds to the alloy below the solubility limit of sulfur in nickel at $625^{\circ} \mathrm{C}(10 \mathrm{ppm} \mathrm{S})$ than for $\mathrm{Ni}-16 \mathrm{~S}$ above this Timit.

Figure 4 gives the depth of intergranular grooves versus heating time at $625^{\circ} \mathrm{C}$. It is proportional to the segregated amount of sulfur. In this figure, depth increases for $\mathrm{Ni}-8 \mathrm{~S}$ and $\mathrm{Ni}-16 \mathrm{~S}$ and reaches two different constant Tevels after four days of temperature treatment but we observe a maximum in the case of $\mathrm{Ni}-16 \mathrm{~S}$ for two days.

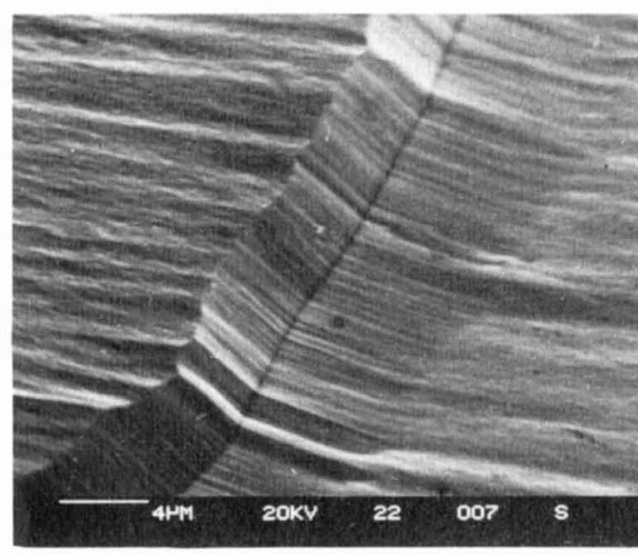

Fig. $2 \mathrm{a}$ - Pure $\mathrm{Ni}, 1050^{\circ} \mathrm{C}-4$ hours Weak electrochemical groove

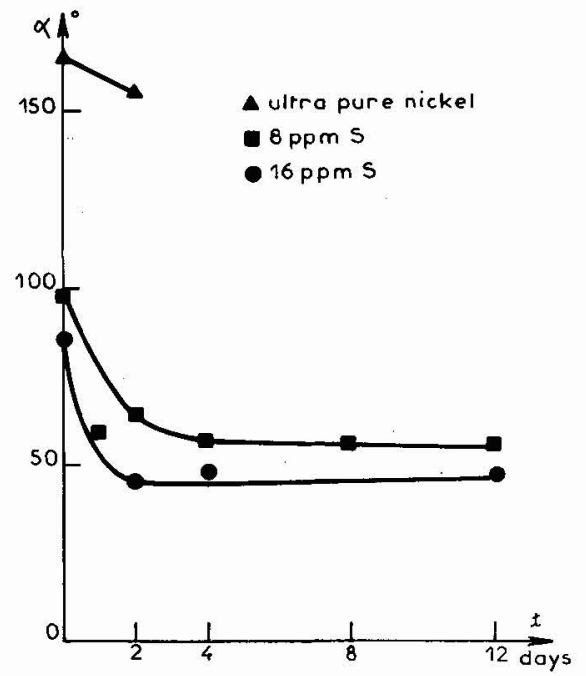

Fig. 3 - Evolution of the average angle of the intergranular groove versus the time of segregation treatment at $625^{\circ} \mathrm{C}$.

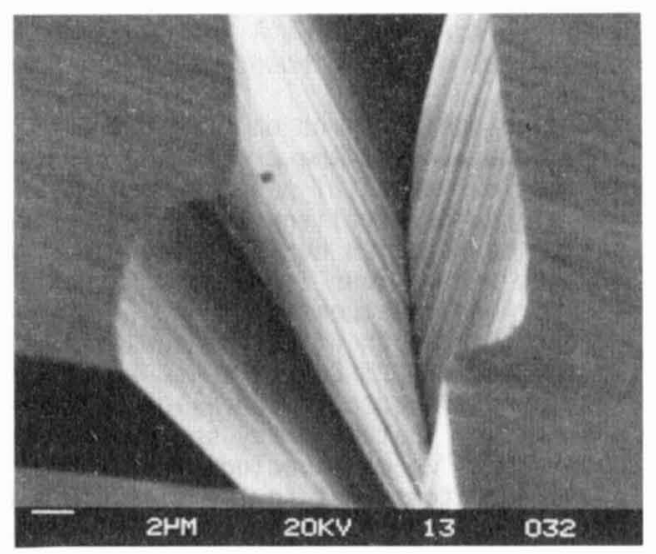

Fig. $2 \mathrm{~b}-\mathrm{Ni}-16 \mathrm{~S}, 1050^{\circ} \mathrm{C}-4$ hours

$$
+625^{\circ} \mathrm{C}-2 \text { days. }
$$

Sharp and deep electrochemical groove

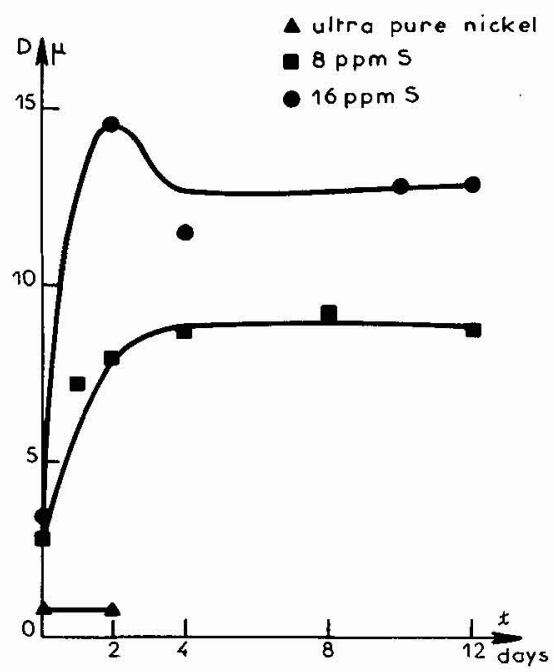

Fig. 4 - Corrosion penetration at grain boundaries versus the time of segregation treatment at $625^{\circ} \mathrm{C}$. 
We note that for ultra pure nickel no evolution is revealed. This low value of penetration corresponds to non segregated grain boundaries (Fig. 4).

For the specimen $\mathrm{Ni}-8 \mathrm{~S}$, below the limit of solubility, a kinetical evolution of segregation occurs up to four days and then the segregation reaches a limit value for longer time of treatment up to twelve days. In the case of Ni-16S, above the solubility limit, the same evolution is observed but with a maximum of corrosion for two days of treatment; this last fact can be explained either by a morphological change of grain boundaries structure or by a precipitation between two and four days of annealing but, up today, any experimental observation can confirm these hypothesis.

In this study we have observed that the ultra pure nickel is poorly attacked because we have numerous twins and low energy grain boundaries; only some high energy grain boundaries are attacked with no segregation but with disordered structure effect they represent $2 \%$ of al1 grain boundaries. For $\mathrm{Ni}-8 \mathrm{~S}$ and $\mathrm{Ni}-16 \mathrm{~S}$, our results give 80 and $82 \%$ of grain boundaries well sensibilized by sulfur.

For each specimen and each heat treatment we study twenty grain boundary grooves to take into account the cristallographical structure of each interface. If we attribute the low values of penetration to low misorientation or coincidence boundaries and the higher penetrations to high misorientations /10,11/ it appears on Fig. 5 that sulfur segregation during twelve days multiplies the corrosion penetration by two for low and by four for high misorientation boundaries. On the same figure one can see for the treatment of $1050^{\circ} \mathrm{C}-4$ hours on $\mathrm{Ni}-16 \mathrm{~S}$ a spread of $5 \mu$ on the corrosion penetration depth of the nonsensitized $\mathrm{Ni}-16 \mathrm{~S}$ while the spread is $20 \mu$ for the $\mathrm{Ni}-16 \mathrm{~S}$ segregated at $625^{\circ} \mathrm{C}-12$ days. We can conclude that the segregation strongly enhances the difference of corrosion penetration between high and low misorientations. If one can say that impurity segregation must lower intergranular energy, then from our experiments we can conclude that corrosion is more sensitive to the chemical effect of sulfur atoms that to the possible energy reduction induced by segregation.

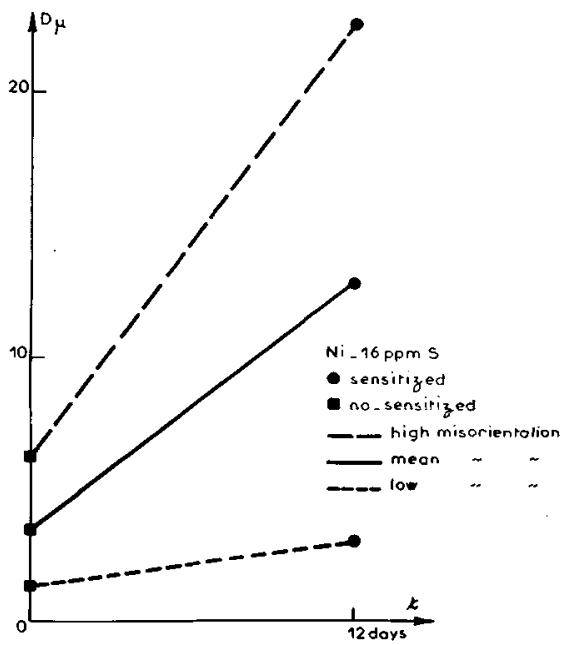

Fig. 5 - Corrosion penetration depth for sensitized and nonsensitized $\mathrm{Ni}-16 \mathrm{~S}$ versus grain boundary misorientation.

Specimens with no segregation $\mathrm{Ni}-\mathrm{OS}$ and with maximum segregation $\mathrm{Ni}-16 \mathrm{~S}, 1050^{\circ} \mathrm{C}-$ 4 hours $+625^{\circ} \mathrm{C}-2$ days, are chosen for observation in the transmission electron microscope and analytical electron microscope.

II - RELATION BETWEEN INTERGRANULAR SULFUR SEGREGATION AND GRAIN BOUNDARY STRUCTURE BY TEM

The present TEM investigation has two strongly connected purposes :

1/ the first one is to study the statistical distribution of grain boundary types as 
a function of the segregation level in $\mathrm{Ni}-\mathrm{OS}$ (specimen without segregation) and $\mathrm{Ni}-$ 165 (specimen with maximum sulfur segregation). These samples have been previously selected by corrosion (cf. part I). Furthermore, crystallographical features (misorientation and grain boundary planes) of the boundaries with a maximum content of segregated sulfur are determined.

$2 /$ besides of its own interest, this part is a required preliminary work to the experiments on segregated sulfur detection by STEM (cf. part III) : for the first analysis, it is necessary to select grain boundaries which are known to contain a maximum sulfur amount.

\section{EXPERIMENTALS}

- Disks foils are extracted from the bulk specimens which have been studied by corrosion. Foils are thinned either by double jet technique for. TEM studies or by ionmilling for STEM studies.

- Crystallographical analysis of grain boundary : once the misorientation is determined, relatively to the reference trihedral, the boundary is classified as "special" or "general" according to a geometrical criterion established in earlier works /14,15/. We consider as "special" al1 C.S.L. boundaries up to $\Sigma=19$ and C.A.D. Finally, the boundary plane is indexed in both crystals.

- The study by TEM is always preceded by an optical microscope examination of the bulk specimen.

II - 1 - STATISTICAL DISTRIBUTION OF GRAIN BOUNDARY TYPES

The very large grain size (\#2 $\mathrm{mm}$ ), did not allow to study more than 20 boundaries for each specimen.

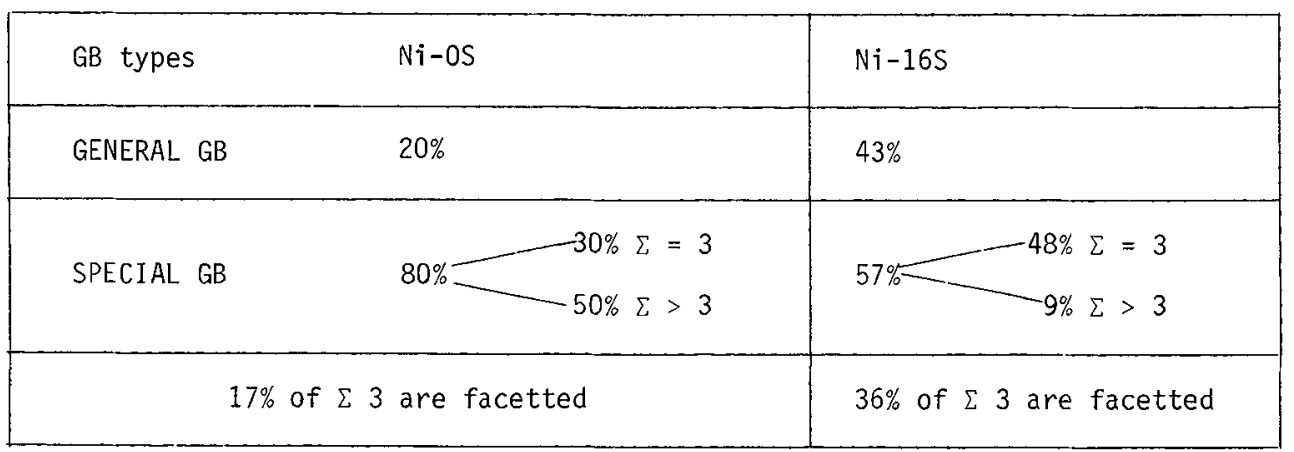

TABLE 1 : Influence of average sulfur segregation on the grain boundary types.

- These results show that the proportion of "special" boundaries (al1 $\Sigma$ up to 19) is a lot higher $(80 \%)$ in the pure $\mathrm{Ni}-\mathrm{OS}$, i.e. in the specimen without segregation, than in $\mathrm{Ni}-16 \mathrm{~S}$. In $\mathrm{Ni}-\mathrm{OS}$, the special boundaries are able to adopt coincidence configurations of any low $\Sigma$. At the opposite, in $\mathrm{Ni}-16 \mathrm{~S}$, the special grain boundaries are nearly all $\Sigma=3$ boundaries. This result has been confirmed by optical micrography of the whole specimens. Until now, no satisfactory interpretation can be done for this phenomenon.

- For the second purpose of this work, the important result of this part is that, in the specimen containing maximum average sulfur segregation, grain boundaries are mainly either general or $\Sigma=3$ boundaries. Furthermore the facetting of $\Sigma=3$ boundaries is more important in this $\mathrm{Ni}-16 \mathrm{~S}$ sample. 


\section{II - 2 - CRYSTALLOGRAPHICAL PARAMETERS OF GRAIN BOUNDARIES WITH A MAXIMUM SULFUR SEGREGATION. INELUENCE OF GRAIN BOUNDARY PLANE. MICROETCHING IN Ni-16S}

The next step is to determine, for a given specimen, in which type of boundary the sulfur is preferentially segregated : during the electrolytical thinning of the foils, some grain boundaries or parts of boundary are selectively microetched. We have shown in a earlier work, that it is possible to establish a correlation between these microetchings and the presence of maximum sulfur segregation (out of precipitation) in the boundary. The microetching is very acute and does not hinder the TEM crystallographical analysis.

Table II summarizes the results in $\mathrm{Ni}-16 \mathrm{~S}$ :

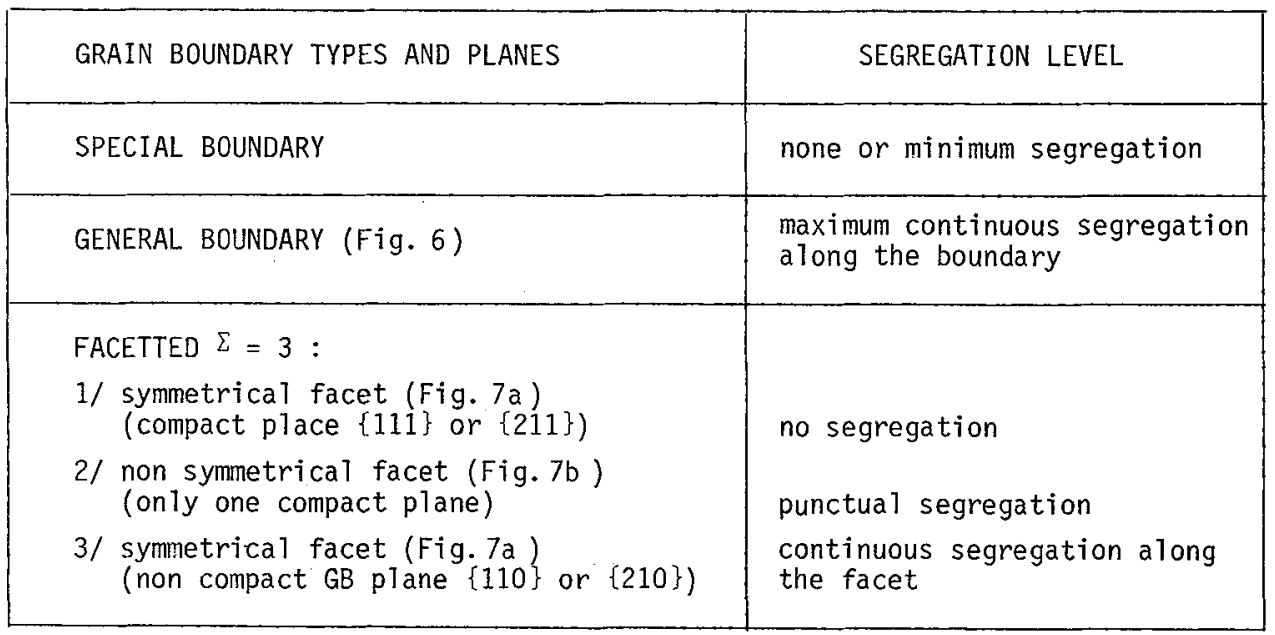

The general boundaries are always continuously microetched (Fig. 6) ; on the other hand, it is necessary to point out that in Ni-OS general boundaries are never microetched, even in the most agressive thinning conditions; these general boundaries are non symmetrical but usually one of the two boundary planes is compact. In $\mathrm{Ni}-16 \mathrm{~S}$, general boundaries are non symmetrical too, but none of the boundary plane is ever compact.

In a facetted $\Sigma=3$ boundary (Fig. 7), sulfur segregates strongly in symmetrical facet $\{110\}$ (or more rarely $\{210\}$ ) but never in symmetrical facets $\{111\}$ or $\{211\}$. These observations are coherent with the different excess volumes and substitutional possibilities predicted by the FCC Hard Sphere Crystals Mode1 /16/. Punctual segregation occurs along non symmetrical facets $\{111\}_{A}\{311\}_{B}$, i.e. When on $1 y$ one grain boundary plane is compact.

From this part, a correlation has been established between the segregation level of a grain boundary and its structure. It enables the choice of interesting areas for STEM investigations.

\section{II - 3 - SELECTION OF APPROPRIATE GRAIN BOUNDARIES FOR EXPERIMENTS OF DETECTION OF INTERGRANULAR SULFUR BY STEM. $(N i-16) S$.}

For obvious reasons, the foils are thinned by ion-milling. After the determination of the grain boundary structure and according to the precedent results, only the foils with general boundary and/or facetted $\Sigma=3\{110\}$ or $\{210\}$ are selected for STEM study. 

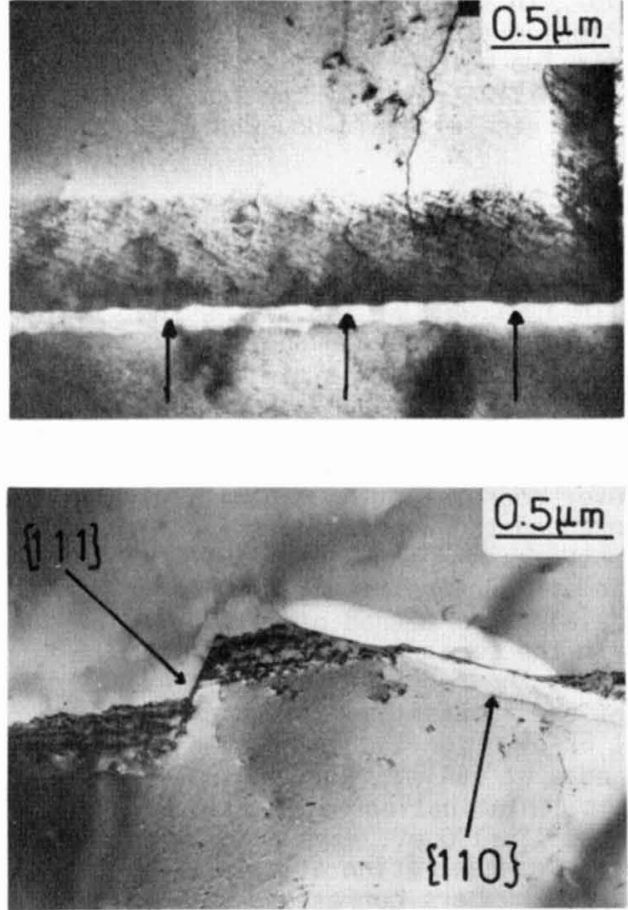

a)
Fig. 6 - Continuous microetching of a general grain boundary in $\mathrm{Ni}-16 \mathrm{~S}$.

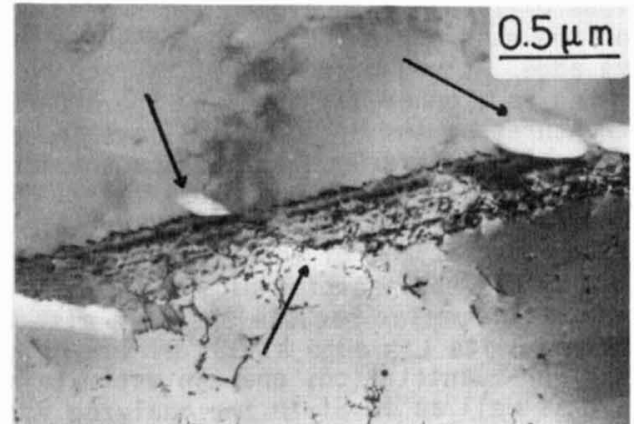

b)

Fig. 7 - Facetted $\Sigma=3$ grain boundary.

a) the symmetrical facet $\{111\}$ is not etched the symmetrical facet $\{110\}$ is continuously microetched

b) the non symmetrical facet $\{111\}_{A}\{311\}_{B}$ is ponctually microetched.

\section{III - DIRECT EVIDENCE, WITH AN ANALYTICAL EM TECHNIQUE, OF SULFUR INTERGRANULAR SEGREGATION}

As a consequence of the very localized nature of this segregation problem, one has to appeal to the high spatial resolution capability of a dedicated analytical STEM $/ 17 /$. Two signals have been used : the ionization edges in an Electron Energy Loss (EELS) spectrum, the characteristic emission lines in an X-ray Emission (EDX) spectrum. When used for the study of a specimen feature such as a grain boundary with plane parallel to the incident beam, it is important to define the extension and localization of the analyzed volume. The irradiated volume is determined by the size and shape of the probe combined with the dimension and shape - rectangular or linear - of the scanned area, together with the beam spread along its propagation through the foil $/ 18 /$. In most situations of the present work, the diameter of the beam at the entrance surface is of the order of 2 to $3 \mathrm{~nm}$; it can increase to about $10 \mathrm{~nm}$ at the exit surface for foils of the order of $60 \mathrm{~nm}$ thick. The actual generation volume of the recorded signal can be slightly different from the irradiated volume. As a matter of fact, the electrons contributing to the EELS signal are collected through the spectrometer entrance aperture so that they are contained within an instrumentally defined cone. X-ray photons in EDX originate not only from the whole irradiated volume but also from specimen areas outside of the beam due to large angle scattered primary electrons. It could therefore be thought that the optimum technique for the detection of an element segregated in a very small volume is EELS performed in conditions chosen to maximise its relative concentration in the analy- 
sed volume as checked in other circumstances $/ 19 /$. In the present study, we have found that the difficulties associated in positioning the probe on the interface in a real problem, introduce limitations so that the two methods (EELS and EDX) perform a nearly equivalent level of performance, as it is iTlustrated by the following analysis on the same grain boundary well defined as a general grain boundary.

\section{EELS ANALYSTS : PERFORMANCES, PROBLEMS AND RESULTS}

For a pure $\mathrm{Ni}$ foil the main core-loss contribution in EELS are the $\mathrm{M}_{23}$ and $\mathrm{L}_{23}$ edges at 65 and $855 \mathrm{eV}$. The presence of $S$ can be revealed by its $L_{23}$ edge at $164 \mathrm{eV}$ with a maximum at $\simeq 200 \mathrm{eV}$ or its $\mathrm{K}$ edge at $2470 \mathrm{eV}$ with a maximum at $2480 \mathrm{eV}$. Using simple considerations involving the relative magnitude of signal, background and crosssections such as explained in $/ 20 /$ it is possible to evaluate the minimum detectable concentrations at about 1 weight $\%$ when using the $S-L 23$ signal and 10 weight $\%$ with the S-K signa?. These estimations assume a satisfactory definition and a possible measurement of the signals after background stripping. If it does not present any serious difficulty concerning the K-edge (of however poor detection capability), it is not the case for the $\mathrm{L}_{23}$ edge of sulfur superposed on the decreasing tail of the $\mathrm{Ni}$ $M_{23}$ edge. As shown in Fig. 8, the energy loss background due to the matrix cannot be fitted to a power-law model in the $100-200 \mathrm{eV}$ domain because of the extended fine structures of the $\mathrm{M}_{23}$ edge. We have therefore developed a method of extracting the S-signa? by difference of two spectra recorded in the same conditions on two adjacent areas on the boundary and close to it. Fig. 9 shows the results of the difference of the two spectra of Fig. 8 after normalization of the intensities in two channel chosen on the maximum of the $\mathrm{M}_{23}$ edge of nickel at $67 \mathrm{eV}$ or on the background at $160 \mathrm{eV}$ just before the position of the searched $S-L_{23}$ edge at $164 \mathrm{eV}$. The problem is even made more complex because there is also a slight contamination with silicon made visible by its $L 23$ edge at $100 \mathrm{eV}$ towering at about $125-130 \mathrm{eV}$. When processing these data for quantitation, one can estimate an average concentration of $\simeq 1-1,5$ weight $\%$ in $S$ as well as in $\mathrm{Si}$ in the analyzed volume. These numbers correspond to a segregation of $\simeq 1 / 3$ to $1 / 2$ of a monolayer of $S$ and $S i$ impurities in the boundary, when taking into account the full width of the analyzed area of the order of $25 \mathrm{~nm}^{2}$.

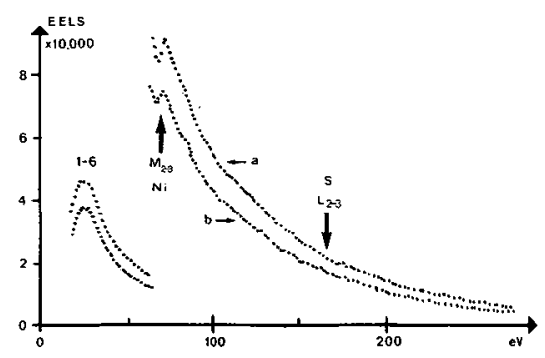

Fig. 8

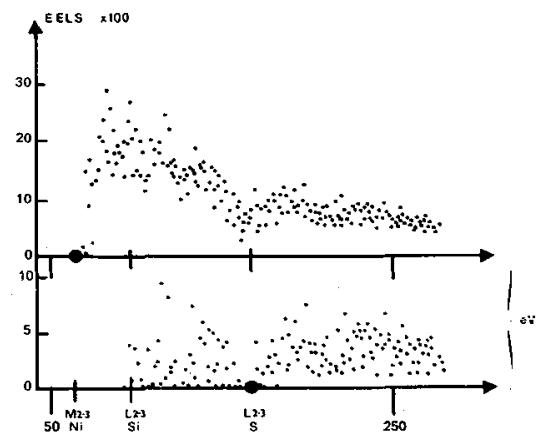

Fig. 9

Fig. 8 - Two spectra recorded in the same conditions (typical area $3 \times 4,5 \mathrm{~nm}$ ) on the grain boundary (a) and on an adjacent area. Recording time per channel is $20 \mathrm{~ms}$ in the plasmon region and $120 \mathrm{~ms}$ in the high energy loss region.

Fig. 9 - Difference between (a) and (b) EELS spectra of Fig. 8 when the intensity is normalized on the top of the $\mathrm{Ni}-\mathrm{M}_{23}$ edge $67 \mathrm{eV}$ (top curve) or at $160 \mathrm{eV}$ just before the S-L23 edge $164 \mathrm{eV}$ (bottom curve) at channels shown by a larger dot. One can estimate the relative $S$ concentration with respect to. the intensity of the $\mathrm{Ni}-\mathrm{L}_{23} \mathrm{Tines}$ (not shown in this figure but recorded in the same scan) by using the following cross-sections values :

$$
\begin{aligned}
& \sigma_{S-L 23}(25 \mathrm{mrad}, 100 \mathrm{eV})=6.6 \times 10^{-20} \mathrm{~cm}^{2} \\
& \sigma_{N i-L 23}(25 \mathrm{mrad}, 100 \mathrm{eV})=2.6 \times 10^{-21} \mathrm{~cm}^{2}
\end{aligned}
$$




\section{EDX ANALYSIS : PERFORMANCES, PROBLEMS AND RESULTS}

Though its poorer definition of the analysed volume, EDX offers a more reproducible way of analysing sulfur in grain boundaries as a consequence of its better performance in minimum concentration (nearly ten times better than for EELS). It results from the weaker background under the characteristic $K$ lines of sulfur and silicon (Fig. 10). In both cases, on the boundary and on the matrix, the irradiated volume is at least three times bigger than in the EELS case. A qualitative comparison of spectra recorded in $\simeq 400 \mathrm{~s}$, clearly shows the presence of $S$ and $S i$ in the boundary (Fig. 11). When processed for quantitation, a typical result of segregation profile is shown in Fig. 12. These data have to be deconvoluted from probe size and beam spreading effects /21/ to offer a more quantitative estimation of sulfur segregation in the grain boundary, which seems to be roughly in agreement with the EELS results. More systematic studies on different types of boundary are now in progress with EDX because it is a simpler-to-use method for controliing the quantitation of sulfur segregation in nickel grain boundaries.

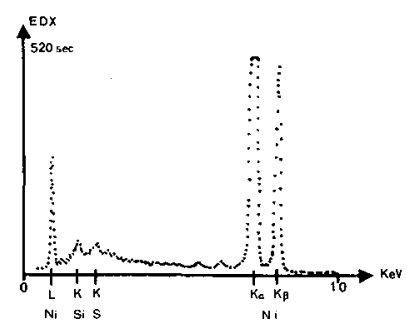

Fig. 10

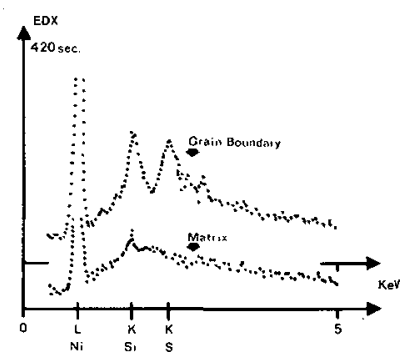

Fig. 11

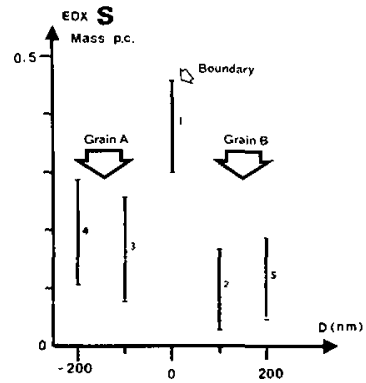

Fig. 12

Fig. 10 - EDX spectrum $(0 \rightarrow 10 \mathrm{keV})$ recorded on the grain boundary.

Fig. 11 - EDX spectra $(0 \rightarrow 5 \mathrm{keV})$ recorded on the boundary and on the matrix.

Fig. 12 - Results of EDX analysis of sulphur for the analyzed volume localized respectively on the boundary and at different positions away from the boundary in both grains $A$ and $B$ (probe size typically $10 \mathrm{~nm}$ ).

It seems difficult to improve these limits of detection because it is impossible at the present time to reduce the analysed volume to the scale of grain boundary dimension.

\section{DISCUSSION}

The general purpose of this work, still in progress, is to establish the most accurately interconnected possible relation between grain boundary structure - quantitative measurements of intergranular sulfur segregation - electrochemical reactivity. This will be the object of the discussion.

As for the correlation electrochemical reactivity - grain boundary structure, the following points may be underlined :

- In $\mathrm{Ni}-16 \mathrm{~S}$ material, the very large spread of electrochemical penetration values can be partly related to the results of TEM study : $81 \%$ of the boundaries exhibit a very deep groove when $83 \%$ of the boundaries are determined as general grain boundaries $(\Sigma=3$ grain boundaries are excluded in these evaluations). This confirms the fact that electrolytic microetching of these general boundaries can be associated to maximum sulfur segregation. 
- In Ni-OS material, 20\% of the boundaries are general but never microetched; only $2 \%$ of all boundaries present a weak but measurable groove. This result is an evidence for the high sensitivity of electrochemical test to segregation and this low percentage can be explained by crystallographical characteristics : one reminds that usually one of the two boundary planes is compact.in these high purity nickel general grain boundaries.

The correlation grain boundary structure - STEM measurements of sulfur segregation has been demonstrated since a sulfur equilibrium segregation has been finally measured in a general nickel grain boundary. Recent experiments indicate that it will be possible to evaluatequantitatively this correlation for other grain boundary structures (special and facetted $\Sigma=3$ ).

This work will be pursued as follows:

- We propose to calculate from numerical values of $\alpha$ and $D$, angle and depth of electrochemical corrosion grooves, a specific parameter to grain boundary : the intergranular atomic volume $(M / \rho) g b$. This last one is characteristic of the atomic disorder and of the nature of the segregated element in the grain boundary. A characteristic evolution has been shown for intergranular $(M / \rho) g b$ versus intergranular sulfur content measured by AES in a technic nickel $/ 2 /$. This calculation wi 11 allow an evaTuation of suTfur content grain boundary by grain boundary and a new correlation with structural and quantitative analysis.

- By TEM the important feature of our resuits is that in Ni-16S the special grain boundaries are nearly a $11 \Sigma=3$ while in $\mathrm{Ni}-\mathrm{OS}$ they are able to adopt any coincidence configuration of any $70 w \Sigma$. This result can be explained either by the presence of sulfur in solid solution in Ni-16S at $1050^{\circ} \mathrm{C}$ or by the phenomenon of intergranular segregation at $625^{\circ} \mathrm{C}$. The determination of statistical distribution of grain boundary types in $\mathrm{Ni}-16 \mathrm{~S}$ heat-treated at $1050^{\circ} \mathrm{C}-4$ hours should allow us to decide between these two hypotheses. Furthermore, a TEM study of the $1050^{\circ} \mathrm{C}-4$ hours, 12 days $625^{\circ} \mathrm{C}$, Ni-16S specimen will be undergone to see if there is any precipitation, in order to explain the diminution of segregation for a heat-treatment longer than two days (Fig. 4).

- Now the X-ray anaTysis by STEM will be performed in order to give a quantitative concentration of the segregated sulfur monolayer. A model is being developed for the $x$-ray generation volume specific to very narrow beam and deconvolution of matrix and grain boundary signals.

\section{ACKNOWLEDGEMENTS :}

This study is supported by C.N.R.S. (ATP $n^{\circ} 2042$ ).

\section{REFERENCES}

1. K.M. OLSEN, C.F. LARKIN, P.H. SCHMI TT Transaction of the ASM 53 (1961) 350-358.

2. L. BEAUNIER, C. CHEFI, A. LARERE, C. VIGNAUD

J. Microsc. Spectrosc. Electron. 7 (1982) 171-183.

3. E.S. MACHLIN, A. LEVI

Scripta Metaliurgica 14 (1980) 127-128.

4. V. VITEK, G.J. WANG

Journal de Physique, Colloque C6, Suppl. $n^{\circ} 12,43$ (1982) 147-161.

5. R.P. MESSMER, C.L. BRIANT

Acta Metallurgica 30 (1982) 457-467. 
6. A. JOSHI

Scripta Metallurgica 9 (1975) 251.

7. T. WATANABE, T. MURAKAMI, S. KARASHIMA

Scripta Metallurgica 12 (1978) 361-365.

8. M. HASHIMOTO, Y. ISHIDA, R. YAMAMOTO, M. DOYAMA Acta Metallurgica 32 (1981) 1-11.

9. R.J. BRIGHAM, H. NEUMEYER, J.S. KIRKALDY Canadian Metallurgical Quaterly 9 (1970) 525.

10. L. BEAUNIER, M. FROMENT, C. VIGNAUD Electrochimica Acta 25 (1980) 1239-1246.

11. L. BEAUNIER, M. FROMENT, C. VIGNAUD

J. Electroana1. Chem. 119 (1981) 125-135.

12. L. BEAUNIER, M. FROMENT, C. VIGNAUD

J. Microsc. Spectrosc. Electron. 8 (1983) 5 a.

13. L. BEAUNIER

Journal de Physique, Colloque C6, Suppl. $n^{\circ} 12,43$ (1982) 271-282.

14. D.H. WARRINGTON, H. GRIMMER

Phi 1. Mag. 30 (1974) 461.

15. 0. KHALFALLAH, L. PRIESTER

Rev. Phys. Appl. 17 (1982) 607.

16. H.J. FROST, M.F. ASHBY, F. SPAEPEN

Report of division of Applied Sciences, Harvard University, June 1982.

17. C. COLLIEX

Proceedings Eurem 84, Budapest (1984).

18. J.P. CHEVALIER, C. COLLIEX, to be published in Dislocation 84,

Eds. P. VEYSSIERE, L. KUBIN and J. CASTAING, Editions du C.N.R.S. (1984).

19. A. BOURRET, C. COLLIEX, P. TREBBIA

J. Phys. 44, (1983) L33.

20. C. COLLIEX

J. Microsc. Spectrosc. Electron. 7 (1982) 525.

21. P. DOIG, P.E.J. FLEWITT

J. Microsc. Spectrosc. Electron. 8 (1983) 193. 